\title{
STRATEGI PENINGKATAN PERAN STAKEHOLDER DALAM PENGELOLAAN MANGROVE DI KABUPATEN TANGERANG
}

\author{
Muzani \\ Dosen Jurusan Geografi FIS UNJ \\ E-mail: Muzaniunj@yahoo.com
}

\begin{abstract}
Mangrove ecosystems have important ecological, economic and social functions that need consideration in coastal development. Mangroves in Tangerang District are being degraded by human activities brought about by a range of stakeholders. The complexity of stakeholders creates problems through various government departments having overlapping jurisdictions. This study aimed to develop strategies to increase the role of stakeholders in the management of mangrove ecosystems in Tangerang regency. Stakeholders were identified from interviews obtained through a snowball sampling method. In the coastal district of Tangerang there are 13 different types of stakeholders involved in mangrove management from government to local people. Each of these stakeholders has an interest and influence in mangrove management. Lack of coordination among stakeholders often results in a variety of management activities. The study recommends strategies to increase the role of stakeholders through improved coordination, information and collaboration among stakeholders.
\end{abstract}

Keywords: stakeholders, management, mangrove.

\section{PENDAHULUAN}

Wilayah pesisir merupakan peralihan ekosistem sumberdaya wilayah pesisir perairan tawar dan laut yang memiliki potensi sumberdaya alam tinggi. Salah satu sumberdaya wilayah pesisir adalah mangrove. Fakta menunjukkan bahwa kerusakan mangrove ada dimana-mana, bahkan intensitas kerusakan dan luasannya cenderung meningkat secara signifikan (Bratasida 2002). Penyebab kerusakan mangrove sangat beragam menurut ruang dan waktu. Secara umum kerusakan mangrove diakibatkan oleh; (1) faktor internal seperti alih fungsi lahan mangrove menjadi tambak, permukiman, industri dan adanya pencemaran limbah, pestisida dan logam berat, (2) faktor eksternal seperti DAS hulu yang menyebabkan tingginya sedimentasi dan akumulasi zat pencemar. Kegiatan konversi mangrove menjadi tambak, kawasan permukiman, dan perindustrian telah menyebabkan degradasi mangrove baik secara fisik maupun habitat.

Penurunan luas mangrove di sepanjang Pantai Utara Jawa berkaitan dengan belum adanya kejelasan tata ruang dan rencana pengembangan wilayah pesisir, pembuangan limbah industri dan rumah tangga, dan sedimentasi akibat pengolahan lahan yang kurang baik. Penyebab yang terbesar adalah konversi mangrove untuk usaha tambak, pemukiman dan kawasan industri secara tidak terkendali. Akibatnya kualitas perairan pesisir merosot tajam, karena intrusi dan abrasi air laut yang tidak dapat dikendalikan. Dampak ekonominya terlihat dari menurunnya persediaan air tawar, pencemaran logam berat dan bahan beracun berbahaya serta menurunnya jenis, jumlah dan kualitas flora dan fauna di ekosistem pesisir. Mangrove di Teluk Jakarta seluas 9.749 ha. Areal mangrove di Teluk Jakarta terbentang mulai dari pantai Tangerang hingga Bekasi. Kawasan ini meliputi tiga daerah administratif, yaitu Kecamatan Muara Gembong Kabupaten Bekasi, Kecamatan Teluk Naga Kabupaten Tangerang, dan Kecamatan Penjaringan Jakarta Utara. Ekosistem Mangrove yang ada di sepanjang pesisir Pantai Tangerang terancam musnah. Kondisi tanaman yang berfungsi menahan gelombang air laut ini sangat memprihatinkan. Sekitar 60-70 persen mangrove yang ada disepanjang pantai utara Tangerang yang memiliki panjang 49 Kilometer saat ini rusak 
parah. Rusaknya mangrove tersebut karena minimnya perhatian pemerintah akan dampak lingkungan yang terjadi disekitar pantai, banyaknya eksploitasi pasir pantai di wilayah Kabupaten Tangerang yang dilakukan oleh orang-orang yang tidak bertanggungjawab serta maraknya pembangunan sejumlah proyek di bibir pantai tersebut. Mengingat pentingnya keberadaan mangrove untuk fungsi ekologisnya dan manfaatnya bagi kesejahteraan masyarakat pesisir, maka perlu dilakukan upaya pengelolaan untuk menjamin kelestarian mangrove.

Dalam pengembangan mangrove, peran pemangku kepentingan dalam bentuk kelembagaan sangat penting terutama sebagai media penyebaran inovasi hasil pertanian (Budi 2009). Kelembagaan adalah suatu sistem organisasi dan kontrol terhadap sumberdaya dan sekaligus mengatur hubungannya (Nasution 2002). Oleh karena itu upaya mengoptimalkan kelembagaan pengelolaan mangrove perlu diupayakan sebagai salah satu alternatif agar terjadi kelestarian ekosistem mangrove.

Kawasan Mangrove di pesisir Kabupaten Tangerang sudah berada pada kondisi yang memprihatinkan. Kawasan mangrove sudah berubah $70 \%$ menjadi lahan tambak. Tindakan konversi ke lahan tambak telah dilakukan sangat tergesa-gesa tanpa perencanaan yang matang. Persaingan prioritas penggunaan lahan antara tambak dan kawasan pariwisata menjadikan populasi mangrove semakin tergeser. Berkurangnya ekosistem mangrove di pesisir Tangerang karena usaha tambak yang dikembangkan di wilayah itu seluas 4.740,79 ha sebagian besar memanfaatkan kawasan mangrove di sekitar pesisir yang mengakibatkan abrasi yang tidak terbendung dan intrusi air laut yang menghancurkan sebagian besar usaha petani. Kerusakan mangrove di wilayah pesisir Tangerang ini salah satunya dikarenakan kurangnya pengawasan dari kelembagaan yang terlibat dalam pengelolaan mangrove tersebut.

\section{METODOLOGI PENELITIAN}

Tujuan penelitian ini adalah mengetahui strategi untuk meningkatkan peran kelembagaan dalam pengelolaan ekosistem mangrove di Kabupaten Tangerang. Penelitian dilaksanakan di pesisir Kabupaten Tangerang. Pemilihan lokasi penelitian ini didasarkan kondisi kawasan mangrove di pesisir Kabupaten Tangerang mengalami degradasi yang masih terus berlangsung. Penelitian dilakukan pada bulan Juli 2013.

Data yang digunakan dalam penelitian ini berupa data primer dan sekunder. Data primer diperoleh dengan cara survei dan melalui pengamatan serta wawancara langsung dengan menggunakan daftar pertanyaan yang telah disusun terhadap stakeholder dan instansi atau pihak-pihak yang terkait. Sedangkan data sekunder diperoleh dari catatan yang berupa laporan atau arsip hasil-hasil penelitian yang relevan dari lembaga-lembaga atau instansi yang terkait. Studi literatur dilakukan dengan mempelajari beberapa dokumen kebijakan pengelolaan mangrove, laporan-laporan, bulletin, jurnal dan dokumen-dokumen lainnya yang relevan.

Analisis data dimulai dengan identifikasi stakeholder yang didapatkan dari hasil wawancara. Dalam mengidentifikasi stakeholder Reed et al (2009) memberikan pedoman atau tahapan untuk melakukan identifikasi terhadap stakeholders yaitu membuat daftar stakeholders yang terlibat dalam pengelolaan mangrove di Kabupaten Tangerang. Sumber data yang dapat digunakan untuk membuat daftar ini adalah hasil pengamatan, informasi dari berbagai masyarakat dan hasil survey. Selanjutnya menentukan kepentingan dan pengaruh dari stakeholder tersebut.

\section{Klasifiikasi stakeholders}

Selanjutnya stakeholders diklasifikasi berdasarkan posisinya dalam pengelolaan mangrove sesuai dengan kriteria yang dibangun oleh Reed et al (2009). Adapun kriteria tersebut adalah:

a. Stakeholder subyek: yaitu stakeholder yang memiliki tingkat kepentingan tinggi dan pengaruh rendah

b. Stakeholder key player: yaitu stakeholder yang memiliki tingkat kepentingan tinggi dan pengaruh yang tinggi terhadap sebuah fenomena 
c. Stakeholder context setter: yaitu stakeholder yang memiliki kepentingan yang rendah dan pengaruh yang tinggi

d. Stakeholder crowd: yaitu stakeholder yang memiliki tingkat kepentingan yang rendah dan pengaruh yang rendah.
Hal ini diperlukan untuk menentukan stakeholder mana saja yang bisa bekerjasama. Gambaran tentang posisi stakeholder dalam pengelolaan mangrove dapat dilihat dalam Gambar 1.

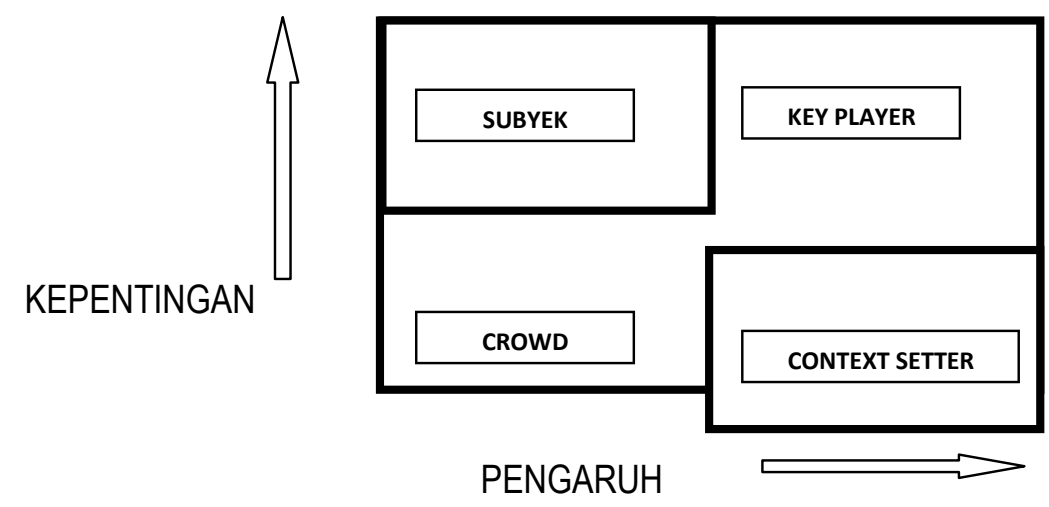

Gambar 1. Matriks stakeholder dan pengaruh serta tingkat kepentingannya

\section{HASIL PENELITIAN}

Stakeholder yang terlibat dalam pengelolaan mangrove

Hasil dari identifikasi stakeholder ditemukan 13 stakeholder di Kabupaten Tangerang yang berkepentingan dalam pengelolaan mangrove (Tabel 1). Berdasarkan daftar stakeholder terlihat pengelolaan mangrove di Tangerang melibatkan berbagai pihak mulai dari pemerintah sampai masyarakat lokal. Beragamnya stakeholder yang terlibat dalam pengelolaan mangrove ini dengan berbagai kepentingannya akan membawa konsekwensi terhadap semakin kompleksnya pengelolaan mangrove. Olehkarena itu diperlukan strategi peningkatan peran kelembagaan agar mampu optimal dalam menjalankan tugas dan fungsinya sesuai dengan aturan yang berlaku.
Klasifikasi stakeholder berdasarkan tingkat kepentingan keterlibatan dan pengaruhnya dalam pengelolaan mangrove dilakukan di wilayah Kabupaten Tangerang. Stakeholder berdasarkan tingkat kepentingan dan pengaruhnya dianalisis pada 4 kelompok stakeholder.

Selanjutnya stakeholder yang telah diklasifikasi berdasarkan pengaruh dan kepentingannya dimasukkan dalam matriks kuadran untuk menentukan subyek, pemain kunci, penghubung dan penonton. Hal ini dilakukan untuk menentukan stakeholder yang bisa melakukan kerjasama dan stakeholder yang memiliki resiko bagi ketidakberhasilan kegiatan. Matriks kuadran posisi stakeholder dapat dilihat pada Gambar 2. 


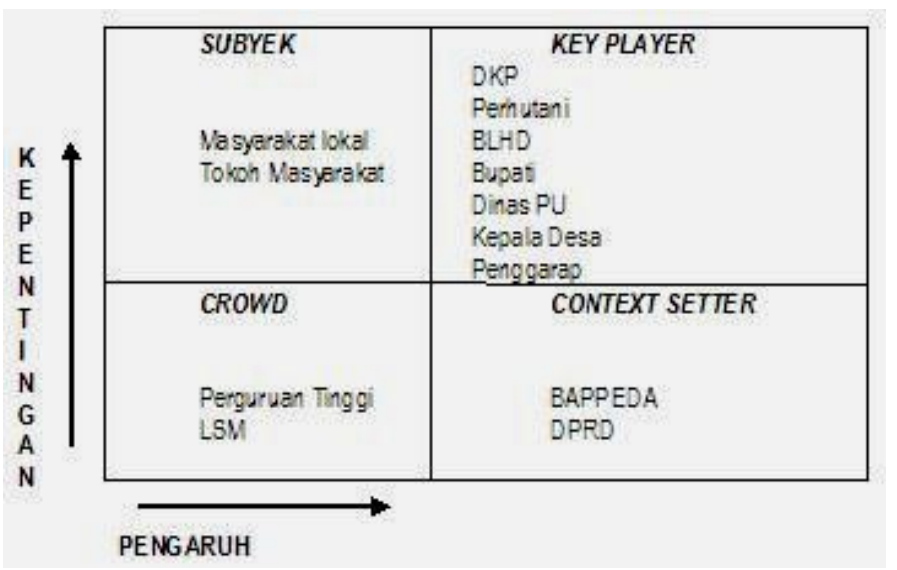

Gambar 2. Matriks kepentingan dan pengaruh stakeholder berdasarkan tugas pokok

Tabel 2 Kepentingan dan pengaruh stakeholders dalam pengelolaan mangrove

\begin{tabular}{|c|c|c|}
\hline Stakeholder & Kepentingan & Pengaruh \\
\hline $\begin{array}{l}\text { Dinas Kelautan dan } \\
\text { Perikanan }\end{array}$ & $\begin{array}{c}\text { Tinggi. Koordinator pengelola di } \\
\text { daerah }\end{array}$ & Tinggi.Pengambil kebijakan \\
\hline DinasLingkungan Hidup & Rendah. Tidak menerima dampak & $\begin{array}{c}\text { Tinggi. Koordinasi terhadap pengawasan } \\
\text { Lingkungan }\end{array}$ \\
\hline Bupati & Tinggi. Penyelenggara & Tinggi. Pengambil kebijakan \\
\hline Perhutani & Tinggi. Koordinator pengelola & Tinggi. Pengambil kebijakan \\
\hline Penggarap & $\begin{array}{l}\text { Tinggi.. Menerima manfaat } \\
\text { dari sumberdaya mangrove }\end{array}$ & $\begin{array}{l}\text { Rendah. Tidak mempunyai } \\
\text { akses terhadap kebijakan }\end{array}$ \\
\hline Perguruan Tinggi & $\begin{array}{l}\text { Rendah. Tidak menerima } \\
\text { dampak }\end{array}$ & $\begin{array}{l}\text { Rendah.Tidak bisa mempengaruhi } \\
\text { keputusan }\end{array}$ \\
\hline Kepala Desa & $\begin{array}{l}\text { Tinggi. Sebagai Pembina masyarakat } \\
\text { sekitar mangrove }\end{array}$ & $\begin{array}{l}\text { Tinggi. Koordinasi pemerintahan } \\
\text { dan kontrol wilayah teritori }\end{array}$ \\
\hline BAPPEDA & Rendah. Tidak menerima dampak & $\begin{array}{l}\text { Tinggi. Kontrol implementasi } \\
\text { perencanaan. }\end{array}$ \\
\hline Dinas PU & $\begin{array}{l}\text { Tinggi. Pemeliharaan infrastruktur } \\
\text { seperti jalan }\end{array}$ & Tinggi.. Koordinasi penataan ruang \\
\hline LSM & Rendah. Tidak menerima dampak & $\begin{array}{l}\text { Rendah. Tidak bisa mempengaruhi } \\
\text { keputusan }\end{array}$ \\
\hline DPRD & Rendah. Tidak menerima dampak & $\begin{array}{l}\text { Tinggi. Dukungan proses } \\
\text { Pengambilan keputusan tingkat lokal }\end{array}$ \\
\hline Masyarakat lokal & $\begin{array}{l}\text { Tinggi. Menerima manfaat dari } \\
\text { sumberdaya mangrove }\end{array}$ & $\begin{array}{l}\text { Rendah. Tidak mempunyai akses } \\
\text { Terhadap kebijakan }\end{array}$ \\
\hline TokohMasyarakat & $\begin{array}{l}\text { Tinggi. Menerima manfaat dari } \\
\text { keberadaan sumberdaya hutan }\end{array}$ & $\begin{array}{l}\text { Rendah. Tidak mempunyai akses terhadap } \\
\text { kebijakan }\end{array}$ \\
\hline
\end{tabular}

Sumber: Analisis Penelitian 2013

Berdasarkan matriks tingkat kepentingan dan tingkat pengaruh yang menempati posisi kuadran A (subyek) di Kabupaten Tangerang terdapat stakeholder, dengan tingkat kepentingan tinggi dan tingkat pengaruh yang rendah yaitu tokoh masyarakat, dan masyarakat lokal. Apabila kegiatan ini ingin melindungi kepentingan mereka, maka diperlukan inisiatif-inisiatif khusus terutama karena mereka adalah merupakan para pihak yang paling besar menerima dampak dari kegiatan ini. Peningkatan kemampuan dan peningkatan kesadaran terhadap hutan mangrove sebagai salah satu sistem penyangga kehidupan merupakan salah satu upaya yang dapat ditempuh untuk melibatkan stakeholder ini dalam kegiatan pengelolaan hutan mangrove di Kabupaten Tangerang.

Posisi kuadran B (key players) di Tangerang terdiri dari Dinas Kelautan dan Perikanan, Dinas Lingkungan Hidup, Bupati, Perhutani, Penggarap, Dinas PU dan Kepala 
Desa. Stakeholder ini merupakan kelompok yang paling kritis karena memiliki kepentingan dan pengaruh yang sama tinggi. Kuadran B ditempati oleh banyak stakeholder dibandingkan dengan Kuadran $A, C$ dan $D$. Banyaknya pihak yang berperan sebagai pemain adalah potensi besar dalam rangka pengelolaan mangrove. Perlu dilakukan kerjasama yang baik agar kegiatan pengelolaan mangrove dapat mencapai kinerja yang diharapkan.

Posisi kuadran C (context setter) di Kabupaten Tangerang terdapat stakeholder, dengan tingkat kepentingan rendah dan tingkat pengaruh yang tinggi yaitu BAPPEDA dan DPRD. Kuadran D (crowd) di Tangerang terdapat stakeholder, dengan tingkat kepentingan rendah dan tingkat pengaruh yang rendah yaitu Perguruan Tinggi dan LSM. Stakeholder ini tidak memerlukan pelibatan intensif dalam pencapaian tujuan kegiatan tetapi apabila memungkinkan, perlu dilakukan monitoring dan evaluasi berkala untuk mengetahui perkembangan kepentingannya. Dari hasil klasifikasi stakeholder tersebut maka untuk mencapai pengelolaan yang baik perlu ada optimasi fungsi dari kelembagaan terutama yang terlibat dalam kelompok key players.

\section{Peran Kelembagaan Dalam Pengelolaan Mangrove}

Dalam pelaksanaan pengelolaan mangrove terlihat peran beberapa stakeholder belum optimal dalam pengelolaan. Bryson (2003) mengatakan belum optimalnya pengelolaan sumberdaya diakibatkan oleh tidak optimalnya peran stakeholder yang dalam menentukan kebijakan.

Mengacu kepada kuadran stakeholder versi Reed (2009) stakeholder yang berpengaruh dalam menentukan kebijakan dalam pengelolaan terdapat pada key stakeholder dan context setter yang terdiri dari Dinas Kelautan dan Perikanan, Dinas Lingkungan Hidup, Perhutani, Penggarap, Dinas PU dan Kepala Desa, BAPPEDA dan DPRD.

Untuk mengoptimalkan peran stakeholder yang berpengaruh pada kebijakan pengelolaan mangrove maka perlu dilakukan strategi pelibatan partisipasi stakeholder key player dan context setter untuk dapat menghalangi atau memblokir kegiatan yang berdampak negatif pada kegiatan pengelolaan mangrove di Tangerang.

Partisipasi merupakan proses keterlibatan stakeholder dalam mempengaruhi dan ikut mengendalikan jalannya rangkaian penyusunan kebijakan yang berdampak kepadanya. Karena itu tiap stakeholder akan memiliki tingkat keterlibatan yang berbedabeda sesuai dengan bobot yang dimilikinya. Bobot yang dimaksud adalah tingkat (kedekatan) kepentingan stakeholder bersangkutan dengan pengambilan keputusan dan kekuatan pengaruhnya terhadap proses penyusunan kebijakan. Adapun partisipasi stakeholder yang seharusnya terlibat dalam pengelolaan mangrove dapat dilihat pada Tabel 3.

Tabel 3 Partisipasi stakeholder pengelolaan mangrove

\begin{tabular}{|c|c|c|c|c|}
\hline \multirow[t]{2}{*}{ Aspek } & \multicolumn{4}{|c|}{ Jenis Partisipasi } \\
\hline & Informasi & Koordinasi & Kolaborasi & Pemberdayaan \\
\hline $\begin{array}{l}\text { Penetapan } \\
\text { Kawasan }\end{array}$ & $\begin{array}{l}\text { - Dinas Kelautan } \\
\text { - dan Perikanan } \\
\text { - Dinas } \\
\text { - Lingkungan Hidup } \\
\text { - Perhutani } \\
\text { - Dinas PU } \\
\text { - Kepala Desa }\end{array}$ & $\begin{array}{l}\text { - Dinas Kelautan } \\
\text { - dan Perikanan } \\
\text { - Dinas } \\
\text { - Lingkungan Hidup } \\
\text { - Perhutani } \\
\text { - Penggarap } \\
\text { - Dinas PU } \\
\text { - Kepala Desa }\end{array}$ & $\begin{array}{l}\text { - Dinas Kelautan } \\
\text { - dan Perikanan } \\
\text { - Dinas } \\
\text { - Lingkungan Hidup } \\
\text { - Perhutani } \\
\text { - Penggarap }\end{array}$ & - \\
\hline Pengelolaan & $\begin{array}{l}\text { - Dinas Kelautan } \\
\text { - Perhutani }\end{array}$ & $\begin{array}{l}\text { - Dinas Kelautan } \\
\text { - Perhutani } \\
\text { - Kepala Desa }\end{array}$ & - Universitas & $\begin{array}{l}\text { - Masyarakat Lokal } \\
\text { - Penggarap }\end{array}$ \\
\hline $\begin{array}{l}\text { Pembinaan } \\
\text { dan } \\
\text { Pengawasan }\end{array}$ & - Kepala Desa & - Kepala Desa & $\begin{array}{l}\text { - Dinas } \\
\text { - Kelautan, } \\
\text { - Perhutani, } \\
\text { - Kepala Desa }\end{array}$ & - LSM \\
\hline
\end{tabular}

Sumber : hasil penelitian 2013 
Berdasarkan tabel 3 diatas jenis strategi partisipasi peran yang bisa dilakukan oleh stakeholder kunci dalam aspek pemantapan dan penetapan, pengelolaan pembinaan serta pengawasan kawasan mangrove adalah memberikan informasi, koordinasi, kolaborasi dan pemberdayaan.

\section{Peningkatan peran dalam informasi}

Memberikan informasi artinya stakeholder kunci harus saling memberikan informasi yang jelas tentang keberadaan mangrove. Selama ini organisasi di lingkungan pemerintah lebih mengetahui informasi internal dibandingkan informasi eksternal. Stakeholder yang berasal pemerintahan cenderung bekerja secara sektoral dan sangat jarang mensosialisasikan kegiatannya pada pihak lain.

Peningkatan peran dalam koordinasi

Jenis partisipasi selanjutnya yang harus dilakukan oleh stakeholder key player adalah melakukan koordinasi. Koordinasi yang dimaksud disini adalah pertukaran informasi kegiatan dua arah antar organisasi sebagai proses perintegrasian kegiatan-kegiatan pembangunan untuk mencapai tujuan yang lebih efisien dan efektif.

Berdasarkan hasil pengamatan di lapangan terjadi kendala dalam melaksanakan koordinasi antara SKPD Pemerintah Daerah dan kantor UPT Kementrian Kehutanan (Perhutani) di daerah dalam pengelolaan hutan mangrove karena masih terdapatnya ego sektoral.

\section{Peningkatan peran dalam kolaborasi}

Langkah selanjutnya adalah melakukan kolaborasi yaitu pembagian peran dan kerjasama di dalam pengelolaan mangrove. Kolaborasi yang terjadi diharapkan akan menjadi sebuah kegiatan berbagi pengetahuan, belajar, dan membangun suatu kesepakatan dan pada akhirnya meningkatkan kesuksesan dalam menyelesaikan suatu masalah. Partisipasi pemerintah dalam kolaborasi adalah berperan dalam mensinergikan kegiatankegiatan pengelolaan mangrove di Tangerang. Perguruan Tinggi juga perlu berpartisipasi dalam bentuk kolaborasi. Perguruan Tinggi bisa berperan dalam pemberdayaan masyarakat, sehingga masyarakat diharapkan mampu mengatasi persoalan dalam dirinya.
Keberadaan Perguruan Tinggi dinilai mampu melakukan transfer pengetahuan dan teknologi kepada masyarakat sehingga terjadi perubahan sosial yang dapat menjamin kelestarian mangrove.

\section{KESIMPULAN}

Berdasarkan hasil penelitian yang dilakukan maka dapat ditarik beberapa kesimpulan bahwa saat ini terdapat 13 kelembagaan yang terlibat dalam pengelolaan ekosistem mangrove di tingkat kabupaten Tangerang baik berasal dari pemerintahan maupun non pemerintahan. Peraturan perundangan yang ada belum mampu memberikan kejelasan kewenangan dan kepastian hak serta masih terdapat tumpang tindih kewenangan pada kelembagaan yang terkait dalam pengelolaan mangrove di. Tangerang. Olehkarena itu perlu strategi peningkatan peran fungsi kelembagaan dalam bentuk fungsi informasi, fungsi koordinasi, dan fungsi kolaborasi.

\section{DAFTAR PUSTAKA}

Asikin M. 2001. Stakeholder Participation In SME Policy Design And Implementation. ADB Technical Assistance SME Development.

Bratasida I. 2002. Pelestarian Ekosistem Mangrove di Provinsi DKI Jakarta. Prosiding Seminar Mangrove DKI Jakarta

Brown K, Tompkins E, Adger WN. 2001. Tradeoff Analysis for Participatory Coastal Zone Decision-Making. Norwich: Overseas Development Group University of East Anglia.

Bryson JM. 2003. What to do when stakeholders matter: a guide to stakeholder identification and analysis techniques. National Public Management Research The Georgetown University, Public Policy Institute, Washington, D.C.

Bryson JM. 2003. What To do When stakeholders Matter: A Guide to stakeholder Identification and Analysis Techniques." A paper presented at the national Public Management Research Conference, 9-11 October 2003, The 
Georgetown University Public Policy Institute, Washington, D.C.

Budi LS, Maarif MS, Sailah I, Raharja S. 2009. Srategi Pemilihan Model Kelembagaaan dan Kelayakan Finansial Agroindustri Wijen. J.Tek. Ind. Pert. 19 (2): 56-63

Munandar A.S. 2001. Psikologi Industri dan Organisasi. Universitas Indonesia Jakarta.

Nasution M. 2002. Meningkatkan Mutu Pengelolaan Hutan Melalui Reaktualisasi Kearifan Masyarakat Hukum Adat dalam Memberdayakan Masyarakat. Lembaga Pengembangan Lingkungan dan
Sumberdaya Manusia kerjasama dengan Uni Eropa. Balikpapan.

Reed MS. 2009. Who is in and why? A typology of stakeholder analysis methods for natural resource management. Journal of Environmental Management.

Sutrisno A. 2011. Penegembangan Institusi pemulihan fungsi Huan Lindung Pulau Tarakan Sebagai Penyangga Pulau Kecil

Uphoff N. 1986. Improving International Irrigational Management With Farmer Partisipation; Getting The Process Right, Boulder CO. West View Press. 